\title{
Teamwork at University in Spain: The Importance of Foreign Students
}

\author{
Rosella Nicolini \\ Department of Applied Economics, Universitat Autònoma de Barcelona, Bellaterra, Spain \\ Email: rosella.nicolini@uab.cat
}

Received 14 January 2015; accepted 2 February 2015; published 4 February 2015

Copyright (C) 2015 by author and Scientific Research Publishing Inc.

This work is licensed under the Creative Commons Attribution International License (CC BY). http://creativecommons.org/licenses/by/4.0/

(c) (i) Open Access

\section{Abstract}

This study discusses the experience of the implementation of a peer-norm in reducing free riding and conflict problems in teamwork activities. This exploratory experiment is run with two cohorts of students in one of the principal Spanish universities. The educational problem is to control for student potential collusion (with clear free riding episodes) in homework projects performed by assigned groups. The peer-norm intends to control for it. The empirical analysis identifies that the success of this norm is associated with the presence of foreign students. Empirically, the presence of foreign students in each cohort brings an educational and cultural background different from the natives' one. Their presence in work groups turns out to be the key factor to reduce potentially the degree of collusion in the overall cohort because they seem to be less concerned by the "social retaliation" of the mates.

\section{Keywords}

\section{Student Behavior, Peer-Norm, Probit Estimation}

\section{Introduction}

This contribution aims at presenting novel evidence about the creation of an ad-hoc peer norm that is expected to limit the free-riding problem in group activity. This evidence refers to a specific case study: the implementation of a new education program in European countries.

The new European Superior Education Space (ESES) program entails important changes in the structure and organization of teaching activity at university level. This education reform applies to European Union countries and it assigns great importance to activities students complete out of the class time. Those activities aim to develop several transversal skills and favor cooperative work. However, the implementation of several group activities outside of the regular teaching hours often gives rise to problems associated with the effectiveness of the 
organization of their tasks and the need to define a device for identifying the individual's contribution to the running of joint projects.

In addition, it has often been pointed out that teamwork may suffer from situations of internal conflicts between group members in the completion of the assigned tasks which affect their accomplishment. The most frequent complaint of the members of the group is indeed about the free-riding problem that is usually reported to the lecturer by the group members individually or in smaller sub-groups (del Canto et al., 2009).

The ESES reform in higher education means that academics face a clear problem of implementing an effective scheme for grading teamwork activities. In order to achieve this scope, it appears to be appropriate to implement incentive devices yielding a typical separating equilibrium (under the viewpoint of the incomplete information theory) for individual evaluations. Economic theory suggests that these are cases in which the engagement of individuals to achieve a target (namely, to complete the teamwork activity) is a truly effective way to overcome the problem of free-riding (Hamilton et al., 2003; Macho-Stadler \& Pérez-Castrillo, 2001). It has also been proven that peer pressure and other factors such as norms, mutual monitoring and empathy to interact, provide the right incentives for getting rid of the free-rider problem and avoiding the pooling equilibrium situation for individual evaluation (Kandel \& Lazear, 1992).

This study deals with the empirical analysis of one of the out-of-class experience encouraged by the ESES reform $^{1}$. In line with the established theoretical framework, and in order to control for the aforementioned freerider problems for the selected out-of class activity, I implemented a specific norm to be applied by all the students enrolled in my class. This norm has been built on the spirit of being able to eliminate conflicts among group members, identify individual participation to the teamwork (and then grading each student appropriately) and limit free-riding or collusive behavior. The aim of the norm is to provide suitable pressure among peers (through mutual monitoring), thereby making them derive the highest utility in revealing private information rather than keeping it as a secret. In practical terms, this translated into the action to declare, quantify and jointly subscribe to each individual's participation and contribution to the teamwork. This produces a situation in which students may effectively differentiate their individual participation in the teamwork (and then, in practice, achieving an expected separated equilibrium). Hansen et al. (2006) have already adopted something similar to study the determinants of productivity performance in a college classroom achieving good results.

Once implemented, this norm allowed a pilot experiment to run in order to collect quantitative information on the individual participation to the teamwork project for two different cohorts of students.

The empirical analysis of these data is informative. In addition to reducing the rate of conflicts, ${ }^{2}$ the implemented norm has enabled the identification of the factors which endorse the students' ability to achieve a stable equilibrium, in which they admit their true contribution to the teamwork. The econometric analysis identifies that the presence of foreign students (mainly Erasmus students) ${ }^{3}$ is the key factor that reduces students' incentives to either cheating or free-riding. In this respect, the adoption of the peer norm allowed achieving the established goal and, hence, a few conclusions about the importance of the heterogeneous composition of the class are put forward as an effective device to reach that goal.

The rest of the paper is organized as follow: Section 2 discusses the organization of the experiment while Sections 3 and 4 analyze and discuss the empirical results. Finally, Section 5 provides conclusions.

\section{Conflict Resolution: The Established Norm and the Experience}

This experiment has been led at the Universitat Autònoma de Barcelona (henceforth, UAB). It has been run in one of the elective courses (External trade) operating as part of the undergraduate business training. This course is quite popular among local students, but also among students coming in from foreign universities mostly under the framework of the Erasmus program.

The experience has been conducted using the two cohorts of students for academic years 2012-2013 and 2013-2014.

\footnotetext{
${ }^{1}$ I am aware that data exploited in this contribution refer to a particular case study. Therefore, I believe that this study delivers interesting exploratory results encourage the further extension of this research line in a properly planned field experiment.

${ }^{2}$ It refers to the conflicts reported to the lecturer as discussed in del Canto et al. (2009). The norm was effective because since its implementation I stopped receiving complains about the involvement of individuals in the making of the group report.

${ }^{3}$ The Erasmus (European Community Action Scheme for the Mobility of University Students) programme is a student exchange programme that has been established since 1987 inside the European Union member states. In order to be eligible to participate to this programme, a candidate must be coursing at university degree or diploma and having completed the first year course.
} 
I have been teaching this course since 2009. In the academic year 2012-2013, the ESES reforms required to organize new forms of evaluation of students (beyond the final exam), generally promoting the implementation of team working. My first concern has been establishing a norm to control the organization of the teamwork, to limit the potential conflict among students and, at the same time, to be effective for grading them individually.

The organization of the teamwork activity follows two main criteria. First, the group activity is a compulsory requirement for all students to pass the course. Second, students are completely free to form their groups and the group size must be between two and six persons, even if my personal suggestion is to aim for a group of 3/4 members ${ }^{4}$. Each group is expected to deliver a report that deals with a case study about the internationalization process of one Spanish firm or brand. The guidelines to produce the report are available on the course webpage. ${ }^{5}$ Once the report has been completed, all member groups are expected to present their report to the rest of the class. Since the beginning of the course, students know that they will be graded individually for this activity. They also know that the final grade for this report will be equally based on the grade of the document they deliver plus their individual presentation.

The challenging point of this action is to be able to differentiate the individual contribution of each student in the writing of the report in order to properly grade him or her individually and limit the free-riding or collusion problem. In order to control for this problem, I introduced a further requirement in the official guidelines of the group project: a type of peer-norm. When producing the report, students are also expected to deliver a joint declaration in a sealed envelope. This declaration is a self-assessment of the individual's participation to the making of the report (usually in percentage of the total work) that must be signed by all the members of the group. Students know that this information will be used to determine the individual final grade for the report exercise, but they ignore the way I will use the information. ${ }^{6}$

Two remarks about the experiment: whereas in the first cohort of the experiment (groups in the academic year 2012-2013) three groups did not turn in the envelope, all the groups turned in this document during the academic year 2013-2014. As a preliminary result, this peer-norm was effective in eliminating any complaint from students about free-riding situations or internal conflict at group level. To the same extent, the norm was also effective in identifying students' participation, because the declarations allowed me to recognize a consistent number of groups that admitted an unequal split of the required tasks for producing the report.

\section{Data and Analysis}

The data gathered during the trial are summarized in Table 1. Overall, this involved 125 students, of whom about $40 \%$ were foreign (Erasmus) students. ${ }^{7}$ As for gender composition, the group is relatively balanced, with $40 \%$ of women. The total number of groups that we are taking into consideration is 35 (in the two years) and they worked on 26 different case studies. ${ }^{8}$ On average, the group consisted of four persons, and $76 \%$ of the groups declared that all members had participated identically (equal split variable) in the tasks assigned to the group work, but with a high variance. Statistics on the participation share (the share partic. variable) identify that, on average, each individual produced $30 \%$ of the group work but there are extreme cases in which a member did not collaborate and the others took care of all of the tasks (refer to statistics about the share partic.).

We begin our analysis by looking at some statistical significant correlations. Table 2 displays the corresponding statistics.

Looking at our pool of data, it is possible to establish that the presence of Erasmus students is directly associated with the smallest groups (in terms of size) and, in addition, their presence is negatively correlated with the

\footnotetext{
${ }^{4}$ It is important to remember that each cohort has no less than 50 students, of whom a significant part is students coming in from other universities (mostly foreign universities). Being an elective course with more than 50 students per year, it is equally likely that the group may be composed of long-term mates or by just foreign students or a mixture of these. In this respect, it is sufficiently reasonable to think of the group formation as being quite random, because none of the previous alternatives dominates the others. Furthermore, I have no possibility to access to the students' admissions files (above all the foreign ones) and I cannot replicate the content of the experience implemented by Moore (2011).

${ }^{5}$ Available at http://rosellanicolini.com/guidelines english.pdf

${ }^{6}$ In this analysis, I am not exploiting the cardinality of the grades of each student. Cardinality will be a measure to study educational performance, but this is not relevant for the scope. A reader will be fine by knowing that all reports were graded above the minimum threshold established by the Spanish educational system to pass an exam or any other type of academic evaluation.

${ }^{7}$ As Erasmus students we identify any foreign (not UAB) student enrolled in the class. The Erasmus programme does not finance a proportion of them because they belong to some interchange agreement signed by UAB with other no EU-universities. We define them all as Erasmus since the aforementioned difference is not relevant for this study.

${ }^{8}$ As a rule, no duplication of case study is admitted in each year, but the same case study can be replicated in two different years.
} 
Table 1. Descriptive statistics.

\begin{tabular}{|c|c|c|c|c|c|}
\hline Variables & Obs & Mean & Std. Dev & Min & Max \\
\hline Gender & 125 & 0.4 & 0.492 & 0 & 1 \\
\hline Erasmus & 122 & 0.418 & 0.495 & 0 & 1 \\
\hline Equal split & 107 & 0.766 & 0.425 & 0 & 1 \\
\hline Share partic & 107 & 29.104 & 17.341 & 0 & 100 \\
\hline Group size & 125 & 4.088 & 1.314 & 2 & 6 \\
\hline
\end{tabular}

Source: own data. Calculus: author.

Table 2. Correlations.

\begin{tabular}{|c|c|c|c|c|c|}
\hline & Group size & Share part & Erasmus & Gender & Equal split \\
\hline \multirow[t]{2}{*}{ Share part } & -0.6554 & 1.0000 & & & \\
\hline & 0.0000 & & & & \\
\hline \multirow[t]{2}{*}{ Erasmus } & -0.5580 & 0.4253 & 1.0000 & & \\
\hline & 0.0000 & 0.0000 & & & \\
\hline \multirow[t]{2}{*}{ Gender } & -0.1423 & 0.0234 & -0.0503 & 1.0000 & \\
\hline & 0.1135 & 0.0000 & 0.5882 & & \\
\hline \multirow[t]{2}{*}{ Equal split } & 0.1753 & -0.0926 & -0.4009 & 0.1527 & 1.0000 \\
\hline & 0.0710 & 0.3426 & 0.0000 & 0.1163 & \\
\hline \multirow[t]{2}{*}{ Decision topic } & -0.4504 & 0.3091 & 0.4248 & -0.0311 & -0.3097 \\
\hline & 0.0000 & 0.0012 & 0.0000 & 0.7309 & 0.0012 \\
\hline
\end{tabular}

Legend: Bold: coefficient significance at $1 \%$. Italics: coefficient significance at $5 \%$ or $10 \%$. p-value below coefficients. Source: own data. Calculus: author.

event of getting a (declared) equal split of the individual participation to the teamwork. As a counterpart of this effect, Erasmus students usually seem to be taking a relatively higher share of participation in the job. In addition, groups with Erasmus students seem also been more pro-active in selecting the topic of the case study (Decision topic variable) in a more autonomous way.

Furthermore, we also performed additional statistics to assess whether Erasmus students tend to be more pro-active in doing on average more work. We rescale the variable share part as the difference between the reported value and the equal-share value. Then, we compute the correlation between this last variables and the Erasmus one. We get no statistical significant correlation that Erasmus students are more prone to take care of the highest part of tasks in the accomplishment of the group work. ${ }^{9}$

In this line of analysis, the econometric exercise confirms the previous preliminary outcomes (Table 3). The values reported in Table 3 are the regression coefficients. We consider as a dependent variable Equal split, namely the declared output of the task division among students. This is a dummy variable that has been built to examine whether all the members of a group split the job equally between them. The equal-share variable is a proper mechanism to control for the moral hazard problem in teams. If students anticipate that by not participating to the group work as much as the correspondent equal-share, they are taking the risk of not having their equal-share in the common declaration and, therefore, being penalized with a lower grade, then they have the right incentive to participate as much as the other group-mates. In this experience, this variable is considered to be a proxy of the typical pooling equilibrium in a signaling game in which it is not possible to discriminate among agents. Given the implementation of our peer-norm, whenever this dummy variable takes the value zero, it is the signal that each member of the group recognizes an uneven individual participation to the accomplishment of the job without incurring in any type of conflicts with the other members of the group. ${ }^{10}$

\footnotetext{
${ }^{9}$ Statistics are available upon request.

${ }^{10} \mathrm{We}$ are also running a robustness check in order to control for the potential problems associated with the independent treatment of the individuals participating to the same group activity. In Appendix A, in Table A1 we report estimations when considering the group as one observation. Erasmus and Gender variables are considered as dummies for the presence in a group of at least one foreign student and a woman respectively. Results do not change with respect to the case presented in Table 3.
} 
Table 3. Probit estimations.

\begin{tabular}{|c|c|c|c|}
\hline & (1) & (2) & (3) \\
\hline Constant & $1.16(1.44)$ & $1.09^{* * *}(0.256)$ & $1.09^{* *}(0.497)$ \\
\hline Group size & $-0.007(0.27)$ & & \\
\hline Erasmus & $-1.49^{* * *}(0.456)$ & $-1.44^{* * *}(0.48)$ & $-1.44^{* *}(0.644)$ \\
\hline Gender & $0.411(0.334)$ & $0.557(0.534)$ & $\mathbf{0 . 5 5 7 ^ { * * * }}(0.144)$ \\
\hline Gender $\times$ Erasmus & & $-0.24(0.674)$ & $-0.24(0.49)$ \\
\hline Time dummy & Yes & Yes & Yes \\
\hline Errors & White (heteroskedastic-robust) & White (heteroskedastic-robust) & Cluster (by subject) ${ }^{11}$ \\
\hline Log likelihood & -47.51 & -47.44 & -47.44 \\
\hline Pseudo R-square & 0.18 & 0.18 & 0.18 \\
\hline Obs. & 106 & 106 & 106 \\
\hline
\end{tabular}

Dependent variable: Equal split; Std errors into brackets. ${ }^{* * *},{ }^{* *},{ }^{*}$ Level of significance at 1\%, 5\% and $10 \%$ respectively.

The probit estimation definitely assesses that the most efficient way to differentiate the individual participation to the teamwork project is to include at least one Erasmus student in the group. This result is robust and consistent across all estimations and error corrections. In contrast, when correcting for the clustering of errors (by product-case study) ${ }^{12}$, the presence of a woman smoothes the differentiation process among the members of the group. ${ }^{13}$

The clear effect of foreign students in tempering the collusion problem is not a novelty in the literature. Watts et al. (2011) identified that the quality of the group work of engineering students improved during the telematic simulation when they were in contact with student teams from other countries. However, this is the first time that it has been possible to assess this effect quantitatively in an econometric exercise.

\section{Robustness Check: Pre-Commitment Threat}

An important factor that could undermine this experiment is the potential pre-commitment agreements among students. This can be a problem not only among persons following the same undergraduate track, but also among Erasmus students if they share other courses or have other common interests, for example.

The pre-commitment option is somewhat endogenous to the culture of a society. Since my groups include peoples from different cultures and bringing very different social norms or habits, I cannot exclude a-priori that the norm introduced in this experience was excluding or dissuading students from this type of collusion.

Of course, this is private information and there is no direct way to assess it. However, I am able to approximate it by referring to the extra information I gathered during the course. In particular, I am referring to the additional individual report that each student is expected to produce. ${ }^{14}$ After providing the group report, each student is required (as a part of the final assessment) to provide an individual report following a working scheme similar to the one followed for the group report. Therefore, if a student participates actively in producing the group report and manage a good knowledge of the data analysis in that work, they would not have any problem in working on the data analysis issues required in the individual report. Therefore, where each group member participates fully in the group report, they would be expected to get a grade for the individual report in line with the one achieved with the group report and presentation. If not, the presence of collusion among the group members must be suspected.

The sample of students providing the group and individual reports is identical. Thus, with the information at hand I created a new variable (comm_index). This variable aims at detecting the potential existence of (stable)

\footnotetext{
${ }^{11}$ The case studies present a different degree of difficulty to deal with them properly. For instance, data or other quantitative information are not always public available and, if this is the case, students are expected to put more effort to accomplish the expected tasks. This further constraint makes them more concerned about the equal split of the job and in the reporting of the effort.

${ }^{12}$ This means taking into account the condition that one product-case study can be repeated from one year to another and so information may circulate among groups belonging to different cohorts.

${ }^{13}$ This result is quite novel because previous evidence usually assesses a positive discrimination versus females in collaborative homework assignments (Parker, 2010).

${ }^{14}$ More information can be found at: http://rosellanicolini.com/exterioren.htm.
} 
commitment agreements among students in order to declare the equal split of the job in the case of recording an individual asymmetric participation to the group report. Accordingly, this is a dichotomy variable that takes value one, whenever a student got two different marks in the two exercises, and zero otherwise. In practice, to be relevant, this difference has to be sufficiently large (more than one point over ten) in order to identify the existence of any pre-commitment mechanism. ${ }^{15}$ I ran probit estimations in order to understand to what extent the norm introduced in this trial was able to control for this collusion threat. Results are presented in Table 4.

We built estimations in Table 4 by exploiting the results shown in Table 3. Irrespective of the type of error correction, the Erasmus variable always displays a significant negative correlation coefficient. As for the variable representing commitment agreements (Comm_index) either it is not statistically significant or it is negative. In case of assuming that the reporting is accurate, no relevant difference is expected to appear between group and individual reports, therefore the comm_index variable is expected to be zero. Instead, in case of recording deviations in individual scores with respect to the group one (that is a signal for the presence of pre-commitment agreements), then the expected sign for the comm_index variable is negative, indeed. Our results point out the presence of potential collusion-type behavior among students that we are able to indentify when adopting a clustering correction for error. There appears to be a clear association in the case where there is a large difference in student performance in the two evaluation activities and the low probability of getting the group-declaration that assesses different individual participation rate to the group report. However, this result does not impact on the statistical significance of our key variable (namely, Erasmus). In this respect, the peer-norm seems being effective because the principal results are not affected by the introduction of this further control.

\section{Conclusions}

This study discusses the outcome of an experiment concerning the introduction of a peer-norm as a signaling device for teamwork tasks. Economic literature allowed formatting a peer-norm yielding to a separating-type equilibrium in a typical signaling game. The exercise turned out to be useful in implementing a mechanism to reduce conflict among teamwork members and allowed them to tailor their individual final grade to their declared participation to the teamwork activity. In this respect, the presence of foreign students in teams tempers the propensity to collude and promotes a separating-type equilibrium. The role of the foreign students is certainly driven in part by their cultural and education background. It is not certainly due to a biased selection composition because UAB (and, in general, Barcelona) is one of the preferred destinations for educational exchange-programs and we host students from all around the world without a clear dominance of one community over the others. Instead, it is possible that the structure of the program (students' stays are limited to one or two terms) makes Erasmus students be less concerned by the potential "social retaliation" of the mates and, therefore, they end-up being the less willing to collude. Then, this behavior generates a positive externality that reduces the degree of collusion in the overall cohort.

To a large extent, these results endorse the importance of maintaining the international interchange programs (as the Erasmus ones) not only for the advantages they may bring in terms of cultural exchange and cohesions in youth generations, but also as a potential effective device to limit distorting behavior in team activities.

Table 4. Probit estimations.

\begin{tabular}{|c|c|c|}
\hline & (1) & $(2)$ \\
\hline Constant & $1.81(0.502)^{* * *}$ & $1.81(0.625)^{* * *}$ \\
\hline Erasmus & $-1.54(0.39)^{* * *}$ & $-1.54(0.604)^{* *}$ \\
\hline Comm_index & $-0.38(0.25)$ & $-0.38(0.18)^{* *}$ \\
\hline Time dummy & yes & yes \\
\hline Errors & White & Cluster (by subject) \\
\hline Log likelihood & -47.14 & -47.14 \\
\hline Pseudo R-square & 0.19 & 0.19 \\
\hline Obs. & 106 & 106 \\
\hline
\end{tabular}

Dependent variable: Equal split; Std errors into brackets. ${ }^{* * *},{ }^{* *},{ }^{*}$ Level of significance at $1 \%, 5 \%$ and $10 \%$ respectively.

\footnotetext{
${ }^{15}$ The rationale behind the creation of this variable is straightforward. Being the expertise required for the two exercises identical, an individual report whose grade is by far lower than the one of the group report unveils that the author did not participated actively to the group report without accumulating the right expertise to produce the second document.
} 


\section{Acknowledgements}

I would like to acknowledge E. Cano for helping me in building up the teaching experience according to the current pedagogical techniques for conflict resolution in student teamwork. I am also indebted to E. Iossa and I. Macho-Stadler for comments and discussions about implementation and interpretation of incentive schemes. Finally, I would like to thanks all the students that participated to these experiences very enthusiastically. Any remaining error is my own responsibility.

\section{References}

Del Canto, P., Gallego I., López, J. M., Mora, J., Reyes, A., Rodríguez E., Snajeevan, K., Santamaria E., \& Valero, M. (2009). Conflicto en el trabajo de grupo: Dos casos representativos. Presented at XV JENUI, Barcelona.

Hamilton, B. H., Nickerson, J. A., \& Owan, H. (2003). Team Incentives and Worker Heterogeneity: An Empirical Analysis of the Impact of Teams on Productivity and Participation. Journal of Political Economy, 111, 465-497. http://dx.doi.org/10.1086/374182

Hansen, Z., Owan, H., \& Pan, J. (2006). The Impact of Group Diversity on Performance and Knowledge Spillover-An Experiment in a College Classroom. NBER Working Paper, n. 12251 (May).

Kandel, E., \& Lazear, E. P. (1992). Peer Pressure and Partnership. Journal of Political Economy, 100, 801-817. http://dx.doi.org/10.1086/261840

Macho-Stadler, I., \& Pérez-Castrillo, D. (2001). An Introduction to the Economics of Information: Incentives and Contracts. Oxford: Oxford University Press.

Moore, R. (2011). The Effect of Group Composition on Individual Student Performance in an Introductory Economics Course. Journal of Economic Education, 42, 120-135. http://dx.doi.org/10.1080/00220485.2011.555694

Parker, J. (2010). An Empirical Examination of the Roles of Ability and Gender in Collaborative Homework Assignments. Journal of Economic Education, 41, 15-30. http://dx.doi.org/10.1080/01615440903382177

Watts, F., García Carbonell, A., \& Rising, B. (2011). Student Perceptions of Collaborative Work in Telematic Simulations. Journal for Simulation/Gaming for Learning and Development, 1, 1-12.

\section{Appendix A}

Table A1. Probit estimations.

\begin{tabular}{cc}
\hline Constant & $(1)$ \\
Erasmus & $\mathbf{1 . 7 5}^{* *}(0.76)$ \\
Gender & $-\mathbf{1 . 5 2}^{* *}(0.65)$ \\
Time dummy & $-0.41(0.334)$ \\
Errors & Yes \\
Log likelihood & White (heteroskedastic-robust) \\
Pseudo R-square & -15.30 \\
Obs. & 0.18 \\
\hline
\end{tabular}

Dependent variable: Group with an Equal split declaration among its members. Std errors into brackets (White correction). ${ }^{* * *},{ }^{* *},{ }^{*}$ Level of significance at $1 \%, 5 \%$ and $10 \%$ respectively. 
Scientific Research Publishing (SCIRP) is one of the largest Open Access journal publishers. It is currently publishing more than 200 open access, online, peer-reviewed journals covering a wide range of academic disciplines. SCIRP serves the worldwide academic communities and contributes to the progress and application of science with its publication.

Other selected journals from SCIRP are listed as below. Submit your manuscript to us via either submit@scirp.org or Online Submission Portal.
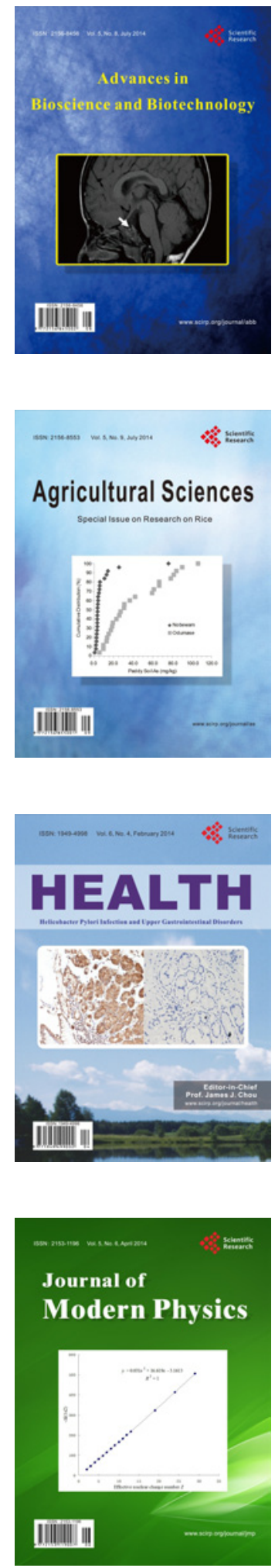
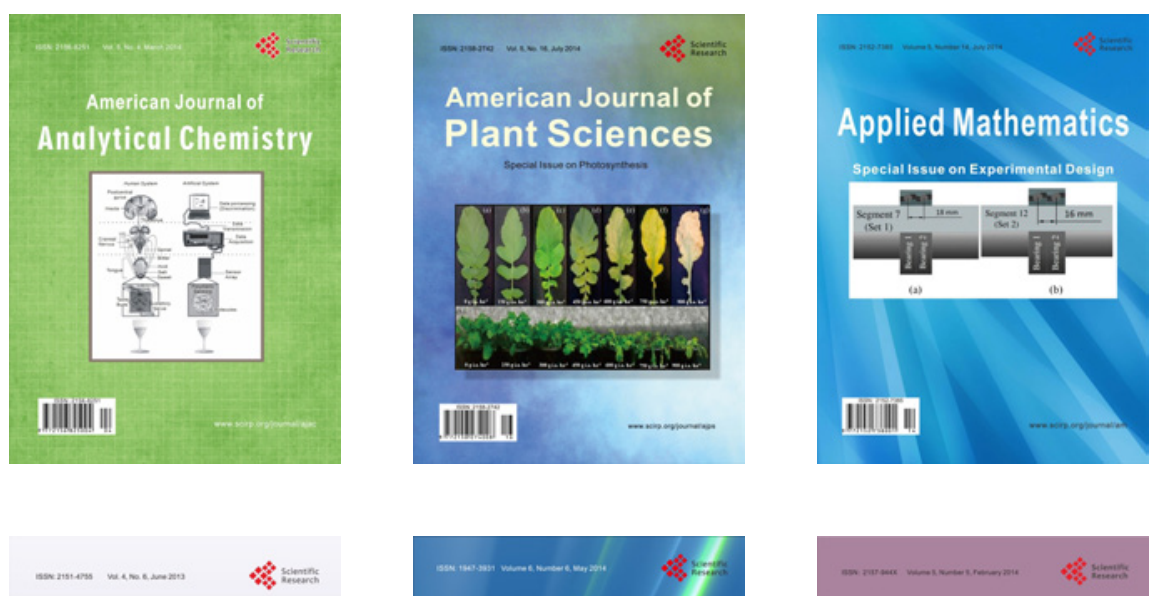

Creative Education
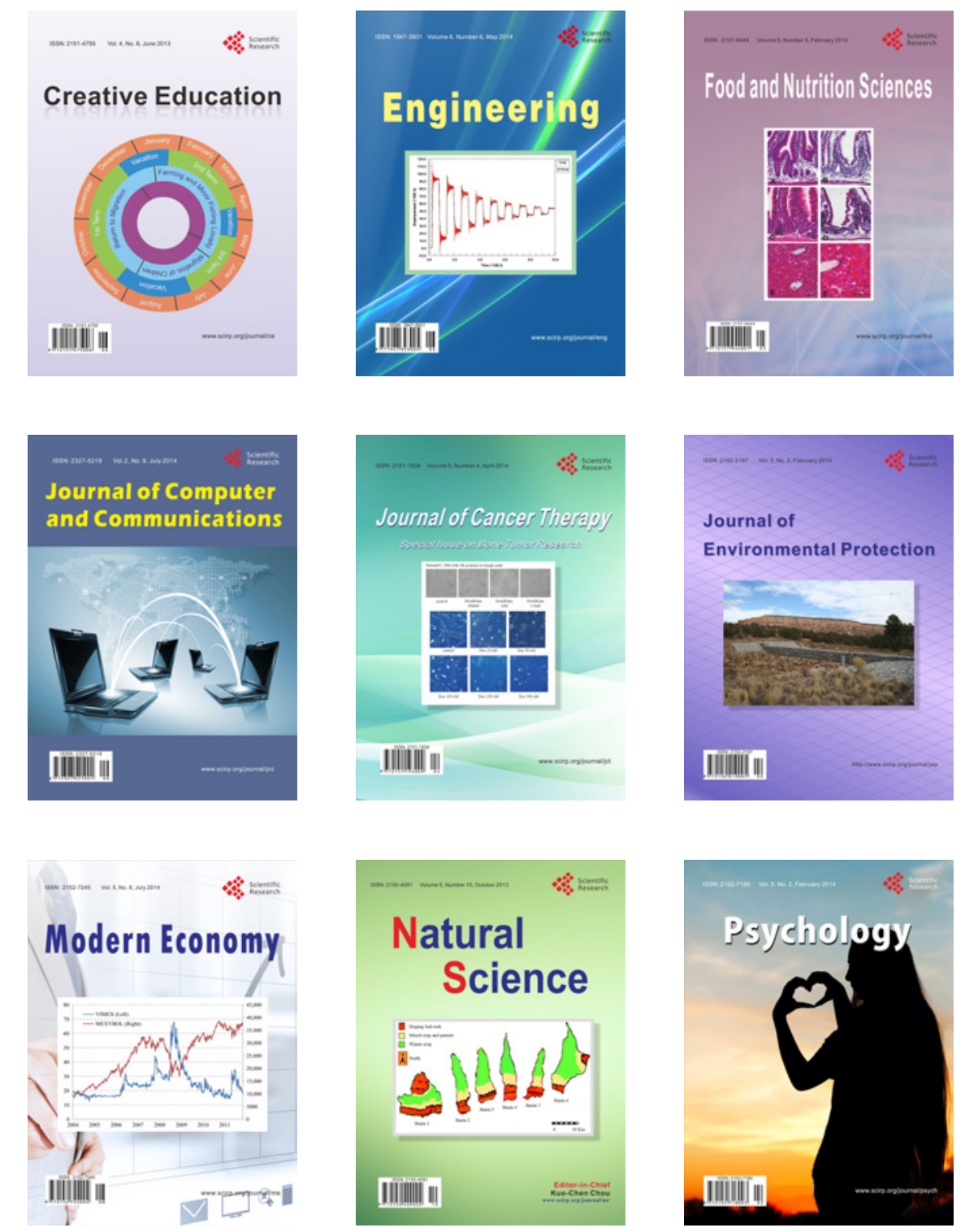